
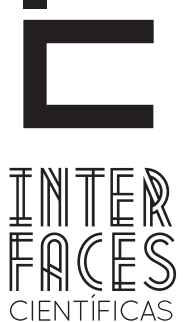

DIREITO

\title{
A EMPRESA DO SÉCULO XXI: CRIANDO VALOR COMPARTILHADO EM TEMPOS DE UM CAPITALISMO CONSCIENTE
}

\author{
Vinícius Figueiredo Chaves $^{1}$
}

\section{RESUMO}

O presente artigo tem o propósito de realizar uma abordagem crítica sobre a empresa, fenômeno complexo e com projeções no Direito, com vistas ao seu redimensionamento à realidade do século XXI. Parte-se do reconhecimento de que, embora a empresa apareça ao Direito (que dela tem de ocupar-se) como fenômeno da vida econômica e também social, impera um modus faciendi que consiste numa metodologia inapropriada para a sua conceituação, que acarreta a sua captação no plano jurídico corriqueiramente por intermédio de seus aspectos meramente econômicos. Tal concepção se manifesta, também, no Código Civil brasileiro, cuja interpretação sistemática permite a consideração da empresa como mera expressão de uma atividade econômica, portanto, um paradigma restrito. 0 trabalho continua com a releitura do fenômeno empresa numa perspectiva ampliada, com abordagem das transformações do direito privado, da perspectiva constitucional brasileira, assim como das teorias dos stakeholders, do capitalismo do valor compartilhado e do capitalismo consciente, que têm em comum a compreensão sobre a necessidade de novos propósitos para a empresa, a partir do reconhecimento de uma maior convergência dos complexos feixes de interesses que a envolvem. Conclui-se que, no século XXI, a empresa não deve ser vista como mera expressão de atividade econômica, como instrumento para a satisfação de interesses exclusivos de agentes racionais que maximizam utilidades, mas sim como a expressão de uma verdadeira instituição, um agente que interage constantemente na realidade social e que reúne diversos feixes de interesses, privados e públicos, os quais devem ser harmonizados.

\section{PALAVRAS-CHAVE}

Empresa. Valor Compartilhado. Capitalismo Consciente. 


\section{ABSTRACT}

This article aims to develop a critical approach to the concept of company, which is a complex phenomenon with impacts on the Law, considering its reshaping to the reality of the 21st century. It is initially recognizing that, even though the company appears to the Law (which must deal with it) as a phenomenon of economic and social life, a modus faciendi takes place that consists of an inappropriate methodology for its conceptualization that entails its uptake in legal terms routinely through their merely economic issues. This conception is also manifested in the Brazilian Civil Code, that systematic interpretation allows considering the company as a mere expression of an economic activity, therefore, a restrict paradigm. The article continues with the second reading of the phenomenon now in a larger context, to approach the transformation of private Law, from the perspective of the Brazilian Consti-

\section{RESUMEN}

En este artículo se pretende hacer un abordaje crítico sobre la empresa, un fenómeno complejo y con proyecciones en la ley, visando su redimensionamiento, frente a la realidad del siglo XXI. El punto de partida es el reconocimiento que, aunque la empresa parezca al Derecho (que de ella se ocupa), como un fenómeno de la vida económica y social, impera la faciendi operandi, que consiste en una metodología inapropiada para su conceptualización, que lleva vigente la financiación legal rutinera a través de sus aspectos puramente económicos. Este diseño también se manifiesta en el Código Civil Brasileño, cuya interpretación sistemática permite la consideración de la empresa como una mera expresión de una actividad económica, por tanto, un paradigma muy cerrado. El trabajo continua con la segunda lectura del fenómeno, ahora en un contexto más amplio, para acercarse a la transformación del derecho privado, la perspectiva constitucional brasileña, así como las te- tution, as well as the theories of stakeholders, of capitalism of shared value of conscious capitalism, which share the understanding of the necessity of new purposes for the company, from the recognition of a larger convergence of complex bundles of interests surrounding it. We conclude that, during the 21st century, the company should not be seen as a simple expression of economic activity, as an instrument to the satisfaction of exclusive interests of rational agents that maximize utilities, but rather as the expression of a true institution, an agent that constantly interacts with the social reality and which unites diverse clusters of interest, both private and public, which must be harmonized.

\section{KEYWORDS}

Company. Shared Value. Conscious Capitalism.

orías de los grupos de interés, el valor compartido del capitalismo y el capitalismo consciente, que tienen en común la comprensión de la necesidad de nuevos propósitos para la empresa, desde el reconocimiento de una mayor convergencia de complejos e inumerosde intereses que lo rodean. Llegamos a la conclusión que en el siglo XXI, la empresa no debe ser visto como una mera expresión de la actividad económica, como instrumento para satisfacer intereses particulares de los agentes racionales que maximizan su utilidad, sino, como la expresión de una verdadera institución, un agente que interactúa constantemente con la realidad social y que reúne a diversos grupos de intereses, públicos y privados, que deben ser armonizados.

\section{PALABRAS CLAVE}

Sociedad; valor compartido, el capitalismo consciente. 


\section{INTRODUÇ̃̃O}

No século XXI se discute a necessidade de novos propósitos para os agentes e instituições sociais, debate que tem a sustentabilidade e governança dos atores públicos e privados como pano de fundo. Tema central dessas discussões parece ser a empresa.

Fenômeno complexo, a empresa teve na sua conceituação um problema recorrentemente discutido por economistas e juristas ao longo dos séculos XIX e XX, com seus reflexos na dinâmica de criação, compreensão e aplicação do Direito. Historicamente, o dado de percepção comum, na doutrina e nos direitos positivos, tem sido a utilização apenas da sua noção econômica para fins de definição.

O Brasil não fugiu ao senso comum: o Código Civil de 2002, embora não a conceitue expressamente, permite a interpretação de sua vinculação como mera expressão de atividade econômica, relacionada com a noção de organização de fatores de produção, o que dificulta a sua orientação no sentido da convergência de um complexo feixe de interesses que a envolve.

0 presente trabalho objetiva discutir a necessidade de redimensionamento da empresa à realidade do século XXI, investigação se justifica em função do destacado papel que esta exerce na sociedade e também pela projeção jamais verificada: pesquisas indicam que, das 100 maiores economias do planeta, mais de metade são "empresas"; suas decisões impactam a vida das pessoas e de países inteiros. Pretende-se a necessidade de redimensionamento dos propósitos da empresa diante de um complexo feixe de interesses, privados e públicos, que precisam ser harmonizados.

A análise crítica da empresa, com vistas ao seu redimensionamento alinhado à realidade do século
XXI, não pode prescindir de uma linguagem dialógica e interativa. Portanto, a metodologia do trabalho é pautada por um caráter transdisciplinar, perpassando categorias não exclusivas do discurso jurídico que impactam diretamente a realidade socioeconômica, em suas mais diversas dimensões.

\section{A COMPLEXIDADE DO FENÔMENO EMPRESA}

Conforme adverte Jorge Manuel de Abreu (1999, p. 10-13), "a empresa aparece ao direito (que dela tem de ocupar-se) como fenômeno da vida econômica e social, como produto da vida". Seria possível, pois, tomar caminhos diferentes para o almejado deslindar da "empresarialidade". Segundo o autor, "uma das vias oferecidas passa pela análise da linguagem corrente ou cotidiana, pela semântica do significante 'empresa' (ou outros equivalentes)". Outra seria a análise econômica da empresa, isto é, examinar o fenômeno pré-jurídico da empresa "solicitando as lições da ciência econômica”. Uma terceira possibilidade seria captar a realidade social-empresarial por intermédio da sociologia.

Embora existam outras possibilidades de investigação das definições meta ou pré-jurídicas da empresa, o fato é que, conforme alerta o professor de Coimbra, há uma espécie de modus faciendi na transposição do pré-jurídico para o fenômeno jurídico-empresarial, no sentido da utilização do "método ontológico" de definir ou de formar conceitos. Tal modus faciendi, revela o autor, consiste numa metodologia inapropriada para uma inequívoca captação do fenômeno em seu plano jurídico, afinal (ABREU, 1999, p. 14-15),

Primeiro: não está provado que a empresa apresente inequívoca identidade no mundo do ser e permita, 
portanto, uma inequívoca captação. Pelo contrário investigações de diferentes quadrantes (econômicos, sociológicos, etc.) têm-nos proporcionado imagens variadas dela; e as divergências reiteram-se no próprio seio de cada ramo do saber. Segundo: mesmo que por hipótese, se alcançasse a (uma única) definição pré-jurídica de empresa - ou, noutra perspectiva (não ontológica), o signo "empresa estivesse solidamente codificado ao nível metajurídico -, era mister provar que o direito recebia cabalmente, ou (mais precisamente) tinha de receber, essa definição (ou a significação do signo codificado).

Nos conceitos formulados ao longo dos séculos XIX e XX, conforme se verá adiante, a identificação da empresa com aspectos meramente econômicos consistiu a tônica das análises, tendo sido a mesma captada pela ótica de um direito privado ainda não conformado por uma série de transformações pelas quais passaria ao longo do século XX. Neste sentido, propõe-se aqui uma abordagem ampliada do fenômeno empresa, voltada para a realidade brasileira, em busca de um possível redimensionamento ao século XXI.

\section{O PROPRIUM DO FENÔMENO EMPRESA SOB A ÓTICA DO DIREITO PRIVADO BRASILEIRO}

O proprium consiste na característica essencial do objeto de estudo. Antes, contudo, de enfrentar a concepção de empresa adotada no direito privado brasileiro, importa esclarecer que os ordenamentos jurídicos se posicionaram de maneiras bastante diferenciadas em relação à expressão, emprestando ao vocábulo distintas significações. Neste sentido, oportunas as observações de Alfredo Hernandez (1986, p. 207-209):

El derecho francés usa los términos enterprise, founds de commerce y achalandage. El Código de Comércio francés usa la palavra empresa cuando realiza la enumeración de los actos objetivos de comercio, al igual que los hacen otros códigos que siguieron al francés, entre ellos el venezolano [...] En el derecho alemán, el Código de Comercio usa la palavra empresa com criterio subjetivo e ignora la noción jurídica de fondo de comercio, al cual no reconoce sino um valor económico. Los alemanes usan la expression Firma (nombre comercial), noción que sólo aparece em las empresas importantes y em las sociedades [...] En Italia, el Código Civil se refiere al empresario (imprenditore) como la persona que ejerce professionalmente una actividad económica organizada com fines de produción o de cambio de bienes y servicios. El Código no define la empresa [...] En Espanã, la introducción del término empresa al linguaje jurídico es relativamente reciente y se señala a Garrigues como el autor que ha tratado de divulgar la concepción italiana sobre la instituición, anotándose que el Código de Comercio ignora prácticamente el concepto de empresa. La elaboración del concepto es obra de la jurisprudencia y de la doctrina [...]

No Brasil, com a efetivação da proposta de incorporação de capítulos sobre Títulos de Crédito e Direito de Empresa, o Código Civil de 2002 consagra-se como o núcleo central do direito privado. No âmbito do Direito de Empresa, o legislador buscou inspiração no modelo já empreendido na Itália, a chamada teoria da empresa. As discussões no contexto italiano, portanto, são especialmente importantes para os debates no âmbito nacional, em função da adoção da construção legislativa originária daquele País. Segundo Aldo Fiale (1994, p. 15),

L'impresa si presenta come un fenomeno econômico, prima ancora che giuridico, trattandosi di un' organizzazione essenzialmente fondata su leggi economiche e su principi tenici: il concetto di imprenditore, pertanto, non costituisce un mero paradigma dalla scienzia giuridica, ma risente dela elaborazione dela scienzia dell'economia.

Fiale (1994, p. 15) destaca a existência, na Itália, de uma tese dominante, defendida pelos autores Graziani, Ascarelli e Messineo, que

[...] hanno rilevato che il legislatore, definendo l'imprenditore, ha voluto definire implicitamente l'impresa". Partindo de tal pressuposto, a empresa pode ser definida como "l'attività economica organizzata dall'imprenditore e da lui esercitata professionalmente al fine della produzione o dello scambio di beni o di servizi. 
Com base nestes raciocínios e na averiguação dos artigos 966 e 1142 do Código Civil de 2002, pode-se afirmar que a empresa foi consagrada no direito brasileiro em sua acepção funcional, ou seja, como expressão de uma atividade econômica. Muito embora não tenha sido apresentado um conceito formal, a análise sistemática dos dispositivos do Código não deixa dúvida acerca da adoção deste determinado perfil. Em outras palavras, a identificação da empresa com aspectos meramente econômicos, captada pela ótica de um direito privado ainda não conformado (o diploma legal brasileiro é fruto de projeto de Lei datado de 1975, mas que, no âmbito do Direito de Empresa, copiou o modelo italiano empreendido em 1942) pelas transformações pelas quais passaria ao longo do século XX.

Esta concepção, segundo relata Ana Bárbara Teixeira (2010), acorrenta o referido instituto à crise epistemológica do modelo de desenvolvimento utilizado no século XX, então pautado em crescimento econômico apenas quantitativo e acumulativo. Segundo a autora, o modelo em questão decorreu da dissociação entre a humanidade (sociedade), suas organizações e o meio ambiente e acarretou reflexos no desalinhamento entre os interesses da sociedade e os de suas instituições, especialmente o Estado e as empresas (estas focadas somente em resultados econômicos de curto prazo).

A empresa e, por conseguinte, o Direito de Empresa, padecem de um vício de origem. Foram pensados para uma realidade onde o sujeito que a exerce prescindia de toda a consideração pelos interesses de outras partes, um paradigma restrito, em que cada indivíduo ou grupo de indivíduos age segundo seu próprio interesse, independente perante os valores e guiado de per se. Percebe-se, assim, que a característica essencial (proprium) do fenômeno empresa no plano exclusivo do direito privado brasileiro, ou seja, a sua consideração enquanto mera expressão de uma atividade econô- mica constitui uma perspectiva limitada. Contribui para o estabelecimento de um polo de tensão entre a autonomia privada, isto é, os interesses exclusivos daqueles que assumem o risco pelo exercício da referida atividade, com a ideia de uma vinculação social necessária à preservação de outros interesses, distanciando-se das noções mais atuais sobre sustentabilidade ${ }^{2}$.

Sem dúvida, a questão desafia um olhar mais amplo.

\section{AS TRANSFORMACÕ̃ES DO DIREITO PRIVADO E A NOVA ABORDAGEM PÚBLICA E VALORATIVA DE SEUS INSTITUTOS}

Durante muito tempo o direito privado somente privilegiou os interesses individuais das partes, faltando-lhe uma perspectiva pública de ancoragem em valores e considerações relacionadas ao bem comum (LORENZETTI, 1998). A ausência de tais perspectivas conduziu à proliferação de um conjunto perturbador de ações maximizadoras particulares, destituídas de valores e pautadas por critérios de autorrealização, o que contribuiu para o estabelecimento de fronteiras cada vez maiores entre o privado e o público.

Naquele cenário, o direito privado, então baluarte da sociedade burguesa, regulava as relações entre os particulares unicamente do ponto de vista da liberdade individual, à margem das constituições, numa espécie de primazia material diante do direito constitucional (HESSE, 1995). Esta liberdade se verificava especialmente no campo da economia, espaço em que pouco se vislumbrava a intromissão do Estado ${ }^{3}$ : esperava-se que as ações

2. A sustentabilidade, atualmente, não mais se encontra atrelada exclusivamente ao aspecto ecológico, envolvendo também aspectos econômicos e sociais. Em tópico posterior, a questão será retomada.

3. No que se refere à participação do Estado na economia é possível constatar na doutrina alusões destacadas a pelo menos três paradigmas gerais distintos: Liberal, Social e Pós-Social. Cada visão implicou em uma determinada con- 
individuais racionais levassem ao autoequilíbrio, a partir da concepção de que a busca pelo próprio interesse, restrita pela competitividade, ensejaria o bem social, a produção máxima e o crescimento da economia, tornando desnecessária e indesejável tal interferência (BRUE, 2011).

A partir da Constituição de Weimar (1919) ocorrem relevantes alterações na dinâmica das relações entre o direito constitucional e o direito privado (HESSE, 1995), as quais se espraiaram pelos ordenamentos jurídicos e implicaram um conjunto de modificações ao direito privado. A partir da sua progressiva referencialidade pública, destaca Ricardo Lorenzetti (1998), ocorre uma ampliação de perspectivas que contribui para a reconstrução de muitos de seus institutos tradicionais, os quais sofrem transformações decorrentes de uma abordagem à luz das constituições, passando a representar verdadeiros instrumentos para a consecução de objetivos fundamentais dos estados. Verifica-se uma maior confluência de interesses privados e públicos a nortear uma releitura da dicotomia público-privado e de institutos jurídicos como a propriedade e a empresa, aos quais se passa a atribuir função social.

\section{ORDEM ECONÔMICA CONSTITUCIONAL: A EMPRESA COMO INSTRUMENTO PARA A CONSECUÇÃO DE OBJETIVOS FUNDAMENTAIS DO ESTADO BRASILEIRO}

No plano da Constituição de 1988, a livre iniciativa foi consagrada como um dos princípios fundamentais, políticos e estruturantes do Estado brasileiro, constituindo fundamento da Repúbli-

cepção de intersecções entre economia, direito, sociedade e o próprio Estado, com o poder público assumindo diferentes posições e estratégias em face do cenário econômico em cada contexto histórico. 0 modelo Liberal restou caracterizado pelo respeito às liberdades e intervenção estatal mínima na economia, a qual era guiada pelos próprios ajustes dos livres mecanismos de mercado. ca Federativa do Brasil. De acordo com esta sistemática, não há dúvida de que os particulares ostentam a posição de principais atores da ordem econômica brasileira (BARROSO, 2008), isto é, a iniciativa privada tem a primazia no plano da atividade econômica.

Por outro lado, a livre iniciativa não se limita aos conceitos de liberdade econômica ou liberdade de empresa, pois a Constituição consagra um sistema híbrido, que simultaneamente congrega aspectos liberais e sociais, onde a existência digna e a justiça social compreendem as finalidades maiores da ordem econômica. Conforme professa Luís Roberto Barroso (2009, p. 114), são “regras destinadas a conformar a ordem econômica e social a determinados postulados de justiça social [...]", ou seja, consistem em "disposições indicadoras de fins sociais a serem alcançados" pela sociedade como um todo. Portanto, este valor da justiça social deve se sobrepor aos demais.

A atual concepção constitucional transforma a atividade econômica exercida pelo particular em instrumento para a consecução de objetivos fundamentais do Estado brasileiro. Confere à iniciativa privada um relevante papel, não apenas de busca de interesses econômicos próprios, mas também e principalmente capaz de atender exigências sociais cada vez mais presentes no cotidiano da sociedade brasileira.

A livre iniciativa, portanto, deve se manter compromissada com os valores éticos, voltados à preservação da existência humana em condições dignas (RAMOS, 2012, p. 360). Trata-se, assim, de um conjunto de atribuições transformadoras que transcendem aspectos meramente econômicos, comprometidas com o desenvolvimento do país, melhor qualidade de vida e o bem-estar das pessoas, das quais advém a permanente necessidade de mudanças nos referenciais do empreendedorismo, no sentido do fiel desempenho de uma função social. 


\section{A FUNCC̄Õ SOCIAL DA EMPRESA COMO PRINCÍPIO CONSTITUCIONAL E A MODIFICAÇÃO DAS IDEIAS SOBRE O PAPEL A SER DESEMPENHADO PELAS EMPRESAS NA SOCIEDADE CONTEMPORÂNEA}

Numa visão moderna a Constituição, norma fundamental que confere unidade e coerência ao sistema jurídico (BOBBIO, 1999, p. 58-59), congrega não apenas direitos de defesa do indivíduo em face do Estado, expressando, também, uma ordem de valores que se irradia para as demais áreas do Direito (ERICHSEN, 2014).

No caso brasileiro, a Carta de 1988 consagrou a dignidade da pessoa humana como princípio e como o primeiro dos direitos fundamentais. Sua posição topográfica no texto constitucional revela não apenas seu status superior, enquanto alicerce dos objetivos fundamentais do Estado, assim como uma função de vetor axiológico (MORAES, 2006, p. 14), que privilegia as situações jurídicas existenciais diante das patrimoniais.

A Constituição alçou também a função social da empresa ao status de princípio constitucional, diante do reconhecimento do aumento da importância da atividade econômica exercida pelo particular num regime capitalista, de economia de mercado, onde a ordem econômica é fundada na livre iniciativa. Desse modo, a empresa passa a ser vista como relevante instrumento para a consecução dos objetivos fundamentais da República, concepção que transforma os particulares em atores sociais do processo de desenvolvimento brasileiro e lhes confere relevantes papéis, que ultrapassam a mera busca de interesses econômicos próprios.

Assim, a livre iniciativa deve ser conciliada com os demais princípios norteadores da ordem econômica e com os demais valores consagrados na Constituição
(AMARAL, 2008, p. 115). Neste sentido, embora a empresa privada capitalista esteja atrelada à noção de finalidade lucrativa, "a ênfase está na atualidade em melhorar não apenas o aspecto econômico, mas também o social, bem como a comunidade na qual está inserida" (ARNOLDI; MICHELAN, 2000, p. 159).

\section{A EMPRESA-INSTITUIÇÃO: DOS INTERESSES EXCLUSIVOS PRIVATISTAS AOS INSTITUCIONALISTAS PUBLICISTAS}

Dentro desse cenário de evolução axiológica, oportuno ressaltar a classificação proposta por David Schewerin (2005). Segundo o autor, a empresa passa a ser reconhecida como uma organização viva, cujas obrigações se tornam multidimensionais no sentido de harmonizar a busca de seus interesses particulares, também, com compromissos éticos e sociais, em busca de um crescimento equilibrado e sustentável em longo prazo. Igualmente relevante destacar a concepção crítica apresentada por Nelson Nones (2002, p. 129), segundo a qual "a atual realidade econômica e social e as ações sociais das empresas parecem sinalizar que o conceito de empresa é mais do que uma atividade econômica organizada para a produção ou circulação de bens ou serviços".

Os raciocínios acima indicam a necessidade de ampliar responsabilidades sociais e redefinir o papel e missão das empresas na sociedade (ARNOLDI; MICHELAN, 2000, p. 159), entendimentos que suscitam reflexão sobre o perfil de empresa consagrado no Código Civil de 2002. A acepção funcional (atividade econômica organizada) adotada, vinculada a uma ótica exclusiva do direito privado, representa um paradigma restrito e parece ir de encontro à perspectiva constitucional brasileira, onde a "empresa" deve ser entendida como um agente de transformação, com relevantes papéis a serem desempenhados na sociedade e ação pautada em 
valores em busca da harmonização da efetivação de interesses particulares e públicos, ou seja, como expressão de uma verdadeira instituição.

\section{O CONCEITO DE STAKEHOLDERS E O SURGIMENTO DE UMA NOVA VISÃO PARA A ATUAÇ̃̃O DAS EMPRESAS: O CAPITALISMO DO VALOR COMPARTILHADO}

Por muito tempo o foco excessivo na maximização do retorno de curto prazo aos shareholders (sócios / acionistas) acabou por gerar um contexto de crise no relacionamento das empresas com a sociedade da qual fazem parte, onde restavam claras distorções como informação imperfeita, racionalidade limitada, conflitos de interesses internos e com a própria sociedade, que comprometeram a geração e preservação de valor.

Neste sentido, o advento do conceito de stakeholders ${ }^{4}$ foi fundamental para o surgimento de uma nova visão para a atuação das empresas, que contesta a premissa de que a maximização de lucros para sócios e acionistas seria a sua única finalidade. Em outras palavras, a consolidação cada vez maior da ideia de que as empresas não desenvolvem suas atividades num vácuo social, mas sim diante de questões fundamentais como expectativas, valores, matrizes sociais e processos comunicacionais mais amplos com a sociedade.

A doutrina do capitalismo do valor compartilhado foi cunhada a partir de noções inicialmente idealizadas por Edward Freeman. No livro "Strategic Management: A Stakeholder Approach", o norte-americano

4. Em tradução não literal, o termo tem sido usado para definir um conjunto de "partes interessadas" direta ou indiretamente afetadas pelas atividades econômicas exercidas, tais como: empregados, consumidores, comunidade, meio ambiente, entre outros.

5 .A obra foi publicada em 2010 pela Universidade de Cambridge. ataca a ideia tradicional de que a firma ${ }^{6}$ somente deve considerar os interesses dos seus titulares. A partir do conceito de stakeholders, o autor traça uma nova visão para a atuação da empresa, pautada no entendimento de criação de valor para um conjunto de "partes interessadas". Contesta-se a premissa de que a maximização de lucros para sócios e acionistas seria a sua única finalidade. Conforme ensina Freeman (2010, p. 24-25-26),

In the traditional view of the firm, the shareholder view, the shareholders or stockholders are the owners of the company, and the firm has a binding financial obligation to put their needs first, to increase value for them. However, stakeholder theory argues that there are other parties involved, including governmental bodies, political groups, trade associations, trade unions, communities, financers, suppliers, employees, and customers. Sometimes even competitors are counted as stakeholders - their status being derived from their capacity to affect the firm and its other stakeholders.

Em seguida, Freeman menciona que, no século $X X I$, a empresa deve criar o maior valor possível para todas as partes interessadas, não somente para sócios ou acionistas, já que esta reúne um prisma de variados interesses, tanto no âmbito interno quanto externo, que devem ser, todos, respeitados:

\begin{abstract}
Every business creates, and sometimes destroys, value for customers, suppliers, employees, communities and financiers. The idea that business is about maximizing profits for shareholders is outdated and doesn't work very well, as the recent global financial crisis has taught us. The 21st Century is one of "Managing for Stakeholders." The task of executives is to create as much value as possible for stakeholders without resorting to tradeoffs. Great companies endure because they manage to get stakeholder interests aligned in the same direction. (FREEMAN, 2010, p. 25-26).
\end{abstract}

A visão de Freeman, de alinhamento de interesses de todos os stakeholders, no que tange à noção de

6. Na doutrina estrangeira, muitas vezes a expressão firma é utilizada como sinônima de empresa. No Brasil, a expressão firma é vinculada pelo Código Civil como modalidade de nome empresarial. 
criação de valor compartilhado, foi também seguida e consolidada por Michael Porter e Mark Kramer (2011) e Linn Stout (2012). Na obra "The big idea: Creating Shared Value - how to reinvent capitalism and unleash a wave of innovation and growth", Porter e Kramer (2011) questionam o modelo atual de capitalismo e propõem o seu redimensionamento, assim como o da empresa, cuja ação não pode ser voltada somente para o desempenho econômico-financeiro, especialmente o de curto prazo. Por seu turno, em "The Shareholder Value Myth" (2012), Stout considera um mito a doutrina de criação de valor somente para os shareholders (sócios/acionistas), que vê a empresa como um instrumento cujo único propósito é a perseguição de resultados econômicos, movida por interesses exclusivos de agentes racionais que maximizam utilidades. De acordo com este raciocínio, corrobora-se a percepção de que a empresa deve contemplar, também, as aspirações de todas as partes interessadas, isto é, uma redefinição de seus propósitos.

\section{CAPITALISMO CONSCIENTE: O CAPITALISMO DE VOLTA AOS TRILHOS}

A doutrina do capitalismo consciente foi idealizada pelo norte-americano John Mackey e pelo indiano Raj Sisodia. No livro Conscious Capitalism ${ }^{7}$, publicado em 2013, os autores advogam a necessidade de redimensionamento do capitalismo, em busca de uma forma mais consciente que lhe permita reencontrar as suas raízes.

Tais concepções são baseadas na rediscussão das molduras da livre iniciativa e do propósito das empresas, afinal, estas "desempenham um papel central em nossas vidas e constituem a organização social que mais afeta as pessoas" (MACKEY; SISODIA, p. 283). Neste sentido, questiona-se o pensamento do economista Milton Friedman e da

7. A obra foi publicada originalmente pela Harvard Business Press Books e também no Brasil no mesmo ano. chamada Escola de Chicago, ou seja, o mito da maximização do lucro.

Segundo os autores, alguns acadêmicos e economistas construíram e adotaram uma visão de que seres humanos são maximizadores dos próprios interesses econômicos, em detrimento de todo o resto. Por extensão desta lógica, "as empresas também foram classificadas como meras maximizadoras de lucro", e a lucratividade apontada como seu único objetivo (MACKEY; SISODIA, p. 19).

Esse mito de que a maximização dos lucros consiste na única finalidade da empresa manchou a reputação do capitalismo e colocou em questão também a própria empresa. Para Mackey e Sisodia (2013, p. 22-35), "o capitalismo de livre iniciativa tem de estar enraizado em um sistema ético baseado na criação de valor para todos os stakeholders", o que indica a necessidade de uma reflexão "mais profunda sobre a razão da existência das empresas e sobre como elas podem criar mais valor".

A filosofia do capitalismo consciente é fundada em princípios como o "propósito maior" e a "integração de stakeholders". 0 primeiro propõe a existência de um impacto positivo mais elevado, quando as empresas se encontram baseadas em um propósito maior, concepção em que o propósito, razão de existência da empresa, traduz-se em algo mais do que gerar lucro e criar valor somente para o eventual titular do exercício da atividade. Por seu turno, a integração diz respeito à necessidade de reconhecimento da importância e interesses de outras partes afetadas por tais atividades e a empresa deve otimizar a criação de valor para essa rede abrangente, harmonizando esses interesses (MACKEY; SISODIA, p. 36-37).

Ao adotar os princípios em questão, os autores sugerem que as empresas entram em sintonia com os interesses da sociedade como um todo. Devem, portanto, orientar as suas ações para seus propósitos maiores. 


\section{CONCLUSÕES}

A presente investigação propôs a análise crítica dos papéis e do alcance da empresa nas práticas sociais e nas relações humanas, para o seu redimensionamento ao século XXI.

Ao longo da pesquisa foi possível perceber que a concepção de empresa como mera expressão de uma atividade econômica parece acorrentá-la à ideia de perseguição de resultados econômicos, movida por interesses exclusivos de agentes racionais que maximizam utilidades, que se reflete em ações particulares destituídas de valores e pautadas por critérios de autorrealização. Esta leitura se encontra atrelada a uma espécie de primazia material do Direito Privado diante do Direito Constitucional, com resquícios de fronteiras entre o privado e o público.

Por outro lado, a progressiva referencialidade pública do Direito Privado implica na ampliação desta perspectiva e conduz à consciência de um horizonte estendido, onde a empresa é vista como instrumento de viabilização da promoção de aspirações privadas e públicas, que apresenta uma função econômica, mas também uma função social.

Foram encontrados, nas doutrinas do capitalismo do valor compartilhado e do capitalismo consciente, novos elementos para o redimensionamento da empresa à realidade e necessidades do século XXI, especialmente a partir da lógica constitucional brasileira. Tais teorias se revelaram como marcos teóricos importantes para a compreensão e solução do problema de pesquisa apontado na introdução. Portanto, entende-se como superada a concepção exclusivo-privatista, de caráter meramente individualista, em privilégio de uma abordagem institucionalista, de cunho publicista, ancorada em valores, onde a empresa-instituição é entendida como agente que deve gerar e preservar valor para todas as partes direta ou indiretamente afetadas por suas atividades econômicas. .

Esse debate impõe reflexões sobre as circunstâncias em que as empresas atendem ao interesse público, diante de um paradigma ampliado de Direito Privado, que não se baseia somente na tolerância e na neutralidade; e também de um capitalismo redimensionado, pautado nas perspectivas de valor compartilhado e maior consciência acerca de propósitos superiores. Enfim, a releitura do fenômeno empresa numa perspectiva ampliada. Criar, preservar e compartilhar valor: esta é a chave de tudo!

\section{REFERÊNCIAS}

ABREU, Jorge Manuel Coutinho de. Da empresarialidade (as empresas no direito). Coimbra: Almedina, 1999.

AMARAL, Luiz Fernando de Camargo Prudente do. A Função Social da Empresa no Direito Constitucional Econômico Brasileiro. São Paulo: SRS, 2008.

ARNOLDI, Paulo Roberto Colombo; MICHELAN, Taís Cristina de Camargo. Novos enfoques da função social da empresa numa economia globalizada. Revista de Direito Mercantil, Industrial, Econômico e Financeiro, São Paulo, ano XXXIX (Nova Série), jan./mar., 2000, p. 157-162.

BARROSO, Luis Roberto. A Ordem Econômica Constitucional e os Limites à Atuação Estatal no Controle de Preços. Redae - Revista Eletrônica de Direito Administrativo Econômico. Salvador, n.14, mai./jun./jul. 2008. Disponível em: <http://www.direitodoestado. com/revista/redae-14-maio-2008-luis\%20roberto\%20barroso.pdf>. Acesso em: 18 abr. 2014.

BARROSO, Luis Roberto. 0 direito constitucional e a efetividade de suas normas - limites e possi- 
bilidades da Constituição brasileira. 9.ed. Rio de Janeiro: Renovar, 2009.

BOBBIO, Noberto. Teoria do Ordenamento Jurídico. 10.ed., Brasília: UnB, 1999.

BRUE, Stanley L. História do Pensamento Econômico. São Paulo: Cengage Learning, 2011.

ERICHSEN, Hans-Uwe. A eficácia dos direitos fundamentais na Lei Fundamental Alemã no Direito Privado. In: GRUNDMANN, Stefan et al (Orgs.). Direito privado, constituição e fronteiras: encontros da Associação Luso-Alemã de juristas no Brasil. São Paulo: Revista dos Tribunais, 2014.

FIALE, Aldo. Diritto Commerciale. 9.ed. Napoli: Simone Edizioni, 1994.

FREEMAN, Edward R. Strategic Management: A Stakeholder Approach. Cambridge: Cambridge University Press, 2010.

HERNANDEZ, Alfredo Morles. Curso de Derecho Mercantil. Elementos del sistema mercantil venezolano. Caracas: Universidad Catolica Andres Bello, 1986.

HESSE, Konrad. Derecho Constitucional y Derecho Privado. Madri: Civitas, 2001.
LORENZETTI, Ricardo Luis. Fundamentos do direito privado. São Paulo: Revista dos Tribunais, 1998. MACKEY, John; SISODIA, Raj. Capitalismo consciente. São Paulo: HSM, 2013.

MORAES, Maria Celina Bodin de. O Princípio da Dignidade Humana. In: MORAES, Maria Celina Bodin de. (Coord.). Princípios do Direito Civil Contemporâneo. Rio de Janeiro: Renovar, 2006.

NONES, Nelson. A função social da empresa: sentido e alcance. Novos Estudos Jurídicos, ano VII, n.14, abr. 2002.

PORTER, Michael E.; KRAMER, Mark R. The big idea: Creating Shared Value - how to reinvent capitalism and unleash a wave of innovation and growth. Harvard Business Review. Jan./fev. 2011.

SCHWERIN, David A. Capitalismo Consciente: como criar o sucesso do futuro inspirando-se na sabedoria do passado. 10.ed. São Paulo: Cultrix, 2005.

STOUT, Linn. The Shareholder Value Myth. San Francisco: Berrett-Koehler, 2012.

TEIXEIRA, Ana Bárbara Costa. A empresa-instituição. São Paulo, 2010, 272f. Dissertação (Mestrado em Direito). Pós-Graduação em Direito da Faculdade de Direito da Universidade do Estado de São Paulo, 2010. 